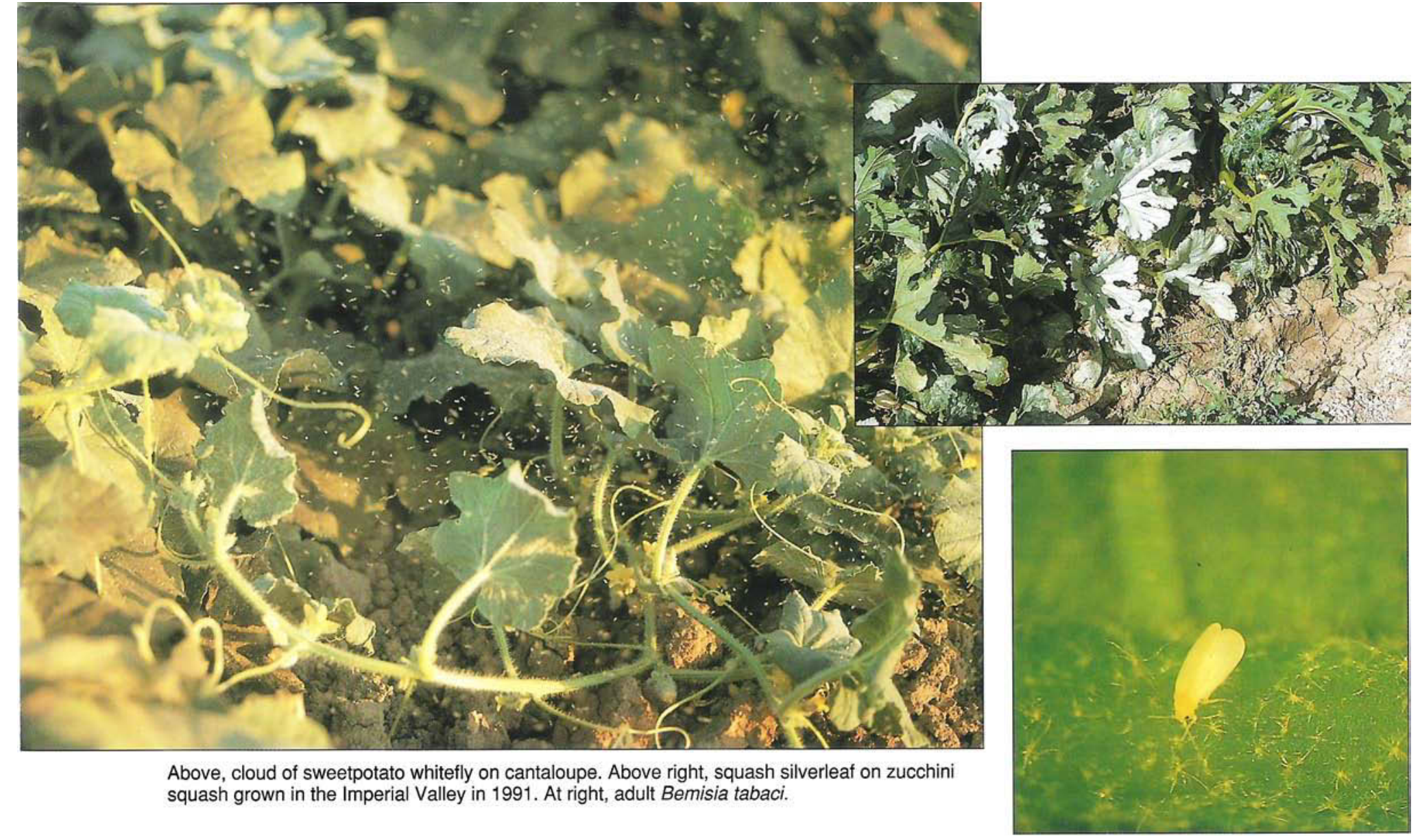

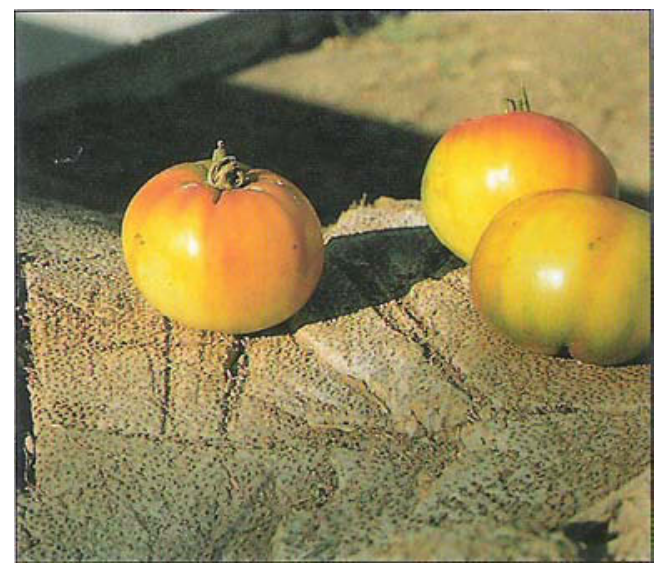

Above, tomato irregular ripening found in the Imperial Valley in 1991. Below, sweetpotato whitefly damage illustrated by cantaloupe fruit covered with honeydew and sootymold fungus.

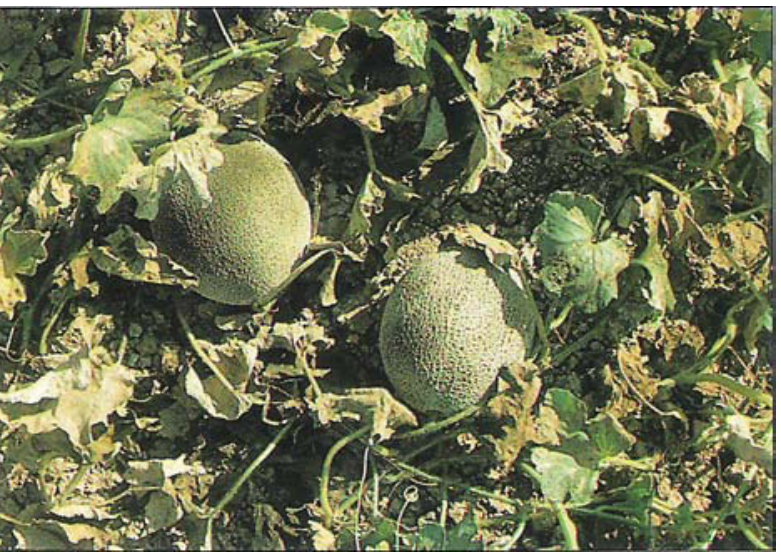

\title{
New strain of sweetpotato whitefly invades California vegetables
}

\author{
Thomas M. Perring $\square$ Arthur Cooper $\square \quad$ Dave J. Kazmer \\ Clyde Shields $\square$ Jon Shields
}

In 1990, a new strain of sweetpotato whitefly invaded Southern California agricultural regions, inflicting heavy damage on cruciferous crops. Problems related to this new strain have impacted vegetable growers throughout California and other growing regions. In the Imperial Valley, 95\% of the 1991 fall melons were disced and total losses to summer and fall crops have been estimated at over $\$ 120$ million.

The sweetpotato whitefly, Bemisia tabaci (Gennadius), causes great concern among agricultural producers throughout the world. It damages plants in several ways including direct damage from feeding individuals, production of honeydew upon which sootymold fungus can grow, and transmission of yield-limiting viruses. The combination of these effects has promoted this species to one of the most damaging pests in agricultural production.

The two strains of $B$. tabaci

Records indicate that $B$. tabaci has been present in Florida since 1894 and California since the 1920s, however it has become a severe problem in both regions relatively recently. In Southern California and western Arizona, 1981 densities of B. tabaci led to widespread whitefly-vectored viruses which caused diseases in many agricultural commodities resulting in record losses. In the 10 years since this reported occurrence, varying densities of B. tabaci and its associated virus complex have caused varying degrees of crop loss. 
Historically, in the Imperial Valley, whiteflies infested cotton in April and May from a limited variety of overwintering weed hosts. Populations increased to high densities in cotton and as the crop was dried down and defoliated in late summer, whiteflies migrated into August and early September-planted cucurbits, where they colonized and spread lettuce infectious yellows virus (LIYV). As cucurbits matured in late October and November, whiteflies moved into surrounding agriculture and combined with the migrating population from cotton to spread LIYV to young lettuce which had emerged in early October. Through the course of our studies, early termination of cotton was evaluated and eventually mandated by the California Department of Food and Agriculture as a management strategy to reduce numbers of overwintering pink bollworm, Pectinophora gossypiella (Saunders). We observed that this early termination led to fewer migrating whiteflies at the time of lettuce emergence and resulted in less LIYV disease incidence in the lettuce crop.

The sweetpotato whitefly situation in Florida has been quite different. In 1986, there were reports of damaging populations in poinsettia greenhouses. Since that time, two particularly severe sweetpotato whitefly-related disorders in vegetables have been observed in Florida; a leaf-silvering symptom on cucurbits known as squash silverleaf and a yellow blotching or streaking symptom on the fruit of tomato known as tomato irregular (or uneven) ripening.

Present knowledge from studies in Florida, California and Arizona suggests that there are at least two strains of $B$. tabaci in the United States. Problems with B. tabaci in Florida first were identified on poinsettia before being associated with vegetable disorders. This strain has been referred to as the "Florida colony," "Florida strain" and more recently the "poinsettia strain." The other identified strain, which occurs in the southwestern desert has been labelled the "Arizona strain," "California colony" and "cotton strain." We will use the terms "poinsettia strain" and "cotton strain."

In comparative studies with the cotton strain, the poinsettia strain 1) causes squash silverleaf, 2) has an expanded host range, 3) produces more honeydew during feeding, and 4) lays more eggs.

\section{Sweetpotato whitefly on broccoli}

In 1990, early termination of cotton was mandated in the Imperial Valley and we expected light whitefly and virus incidence in fall vegetables, much like we had documented in 1989. However, in October we were alerted to a severe infestation of sweetpotato whitefly in a field of broccoli which had been transplanted in the Imperial Valley. At the field, there were high numbers of whiteflies feeding on the plants which resulted in plants half the size of normal, uninfested plants. Melon fields in the valley also were infested with unusually high numbers of whiteflies.

Although $B$. tabaci had been shown in no-choice laboratory studies to utilize broccoli as a host, and it is found commonly on cole crops in India and Israel, immatures of this whitefly rarely were found in Imperial Valley cole crops prior to 1990 . To document this we relied on past and present surveys of cruciferous crops in the valley during which sweetpotato whitefly densities were evaluated. The surveys consisted of frequent (at least weekly) whitefly estimates in broccoli, cauliflower and cabbage fields from late August to early January in 1988, 1989 and 1990. We observed 20 fields in 1988, 45 fields in 1989, and 43 fields in 1990; whitefly adults and immatures were categorized as light, moderate or high levels. These data indicated that 10,12 , and 25 of the fields in 1988, 1989, and 1990, respectively, had moderate to high levels of whitefly adults on at least one sampling date. Since numbers of adults on broccoli likely are comprised of colonizing whiteflies combined with migrating individuals from other crops, a more relevant parameter of whitefly infestation in cole crops was the level of immatures present on the crop over the 3 years. In 1988 and 1989,

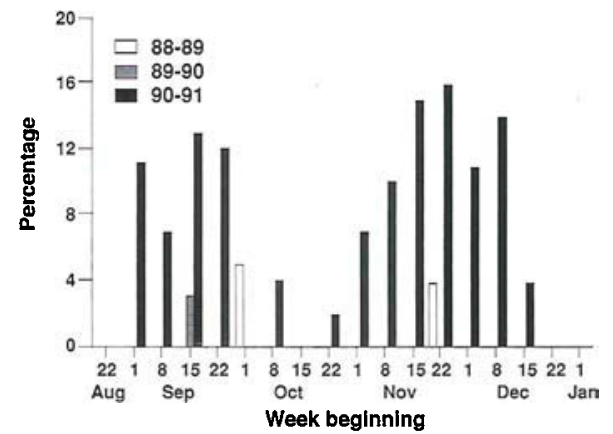

Fig. 1. Weekly percentages of cole crop fields surveyed in 1988, 1989, and 1990 with moderate to high levels of sweetpotato whitefly immatures.

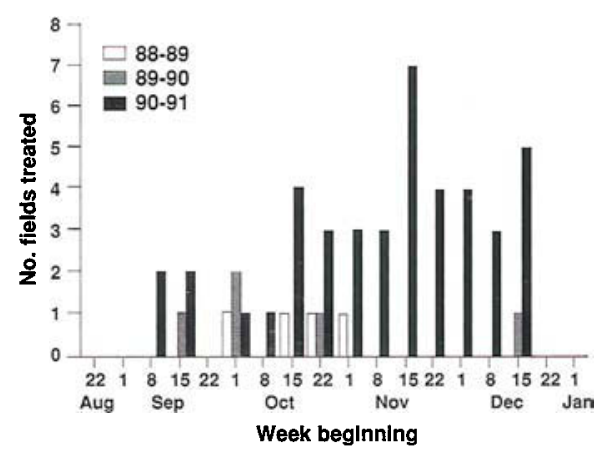

Fig. 2. Weekly numbers of cole crop fields in 1988,1989 , and 1990 treated specifically for sweetpotato whitefly control. low colonization of the cole crops was evident by the immature densities (fig. 1). Only 3 fields of the combined 65 had moderate immature densities at some point in the growing season.

The 1990 immature whitefly estimates differed substantially from counts in 1988 and 1989. Of the 43 fields sampled, 12 had moderate to high immature densities at some time in the growing season. On a weekly basis, densities of immature $B$. tabaci were rated as moderate or worse in at least 1 field on all but 5 sampling dates (fig. 1).

The disparity between 1988, 1989 and 1990 in the densities of colonizing immatures resulted in substantial differences in the frequency of insecticide applications. In 1988, we recommended that insecticides be applied for whitefly control on 4 different field/date occasions (fig. 2). We recommended applications on 5 field/ date occasions (2 fields on October 1) in 1989. The number of applications used in 1990, however, were much higher, and applications were recommended on 42 occasions (fig. 2). With a total number of fields sampled in 1990 of 43, nearly all fields were sprayed an average of at least one time strictly for sweetpotato whitefly control.

Since densities of sweetpotato whitefly immatures were particularly high in 1990 compared to the previous 2 seasons, and because it is uncommon to find an alteration in host preference of the magnitude presented here in a single year, we suspected an introduction of a new strain of $B$. tabaci into Southern California.

\section{Whitefly strain determination}

Two experiments were conducted to test the hypothesis that the new strain of sweetpotato whitefly on broccoli was similar to or the same as the poinsettia strain. Three strains were compared in these experiments. A cotton strain (strain A) was started from whiteflies collected on cotton in the Imperial Valley in 1981 and since has been maintained in the laboratory on cotton and bean. A broccoli strain (strain B) was initiated from adults and immatures collected on broccoli near El Centro, California on February 8, 1991. Some of the adults obtained from this collection were used in the electrophoretic analyses described below while others were used to initiate a colony maintained on mustard. A poinsettia strain (strain C) was established in 1987 and maintained on poinsettia at UC Riverside. Each of the two strains maintained in the laboratory for an extended period (strains $A$ and $C$ ) were initiated with over 100 individuals, maintained at population sizes on the order of at least several hundred individuals, and periodically infused with new material from the field. Thus, it is likely that the 
levels of genetic variation in these laboratory strains are similar to those of field populations.

Experiment I: Electrophoretic variation. Since adults and immatures of the two known whitefly strains (A and C) are morphologically similar, we used electrophoresis to examine variation at enzymeencoding genes or loci ("allozymes" or "isoenzymes"). Owing to the small size of adult whiteflies, a specialized electrophoretic procedure (isoelectric focusing in cellulose acetate membranes) with high sensitivity was used. Electrophoresis separates enzymes based on structural differences and in most cases these differences are heritable or genetic. Differences are indicated by variation in the position of the "bands" or zones of enzyme activity following electrophoresis.

All told, we compared the three strains at 18 allozymic loci. Strains $B$ and $C$ did not differ at any of these loci in terms of the presence or absence of different bands. In contrast, strain $A$ had one or more bands which were not present in strains $B$ and $C$ at six loci. At four of these loci, the difference between strain A and strains B and $C$ was "fixed," that is, each of the bands found in strain A was not found in either strain B or strain C. Overall, the results of the electrophoretic analyses provide no evidence of genetic divergence between the broccoli and poinsettia strains (B and C). Conversely, the cotton strain (strain A) is genetically distinct from broccoli and poinsettia strains. These results support the hypothesis that broccoli and poinsettia strains are derived from the same source.

Experiment II: Biological confirmation. Squash seeds were planted in vermiculite and germinated in a growth chamber. After germination, seedlings were transplanted into 5-centimeter square pots and grown in a greenhouse under natural lighting. When seedlings had three true leaves, 10 plants were placed in each of the three previously mentioned whitefly cultures. After 2 weeks, the seedlings were evaluated for squash silverleaf symptoms. All squash plants placed in the poinsettia strain and broccoli strain whitefly cultures developed silverleaf symptoms. None of the plants grown in the cotton whitefly culture developed this disease.

\section{Discussion}

Prior to 1990, B. tabaci did not infest crucifers to the point of causing concern among producers. The data presented here suggest that this change in the sweetpotato whitefly host range was due to an introduction of the poinsettia strain of $B$. tabaci into the agricultural southwest desert. This report is consistent with simi- lar finds in Arizona in 1989 and 1990. Individuals of the poinsettia strain could have been introduced via broccoli or cauliflower transplants grown in central California bedding plant operations, which may have been in close proximity to ornamental ranges. Also, poinsettia plants sold on the retail market in the Imperial Valley in the late fall and winter were observed to have heavy populations of $B$. tabaci (according to personal communication from E. T. Natwick, Imperial County Farm Advisor).

Regardless of the source of introduction of the poinsettia strain into the Imperial Valley, the implications of this introduction are quite severe. First, the immediate problem of sweetpotato whitefly management on cole crops is apparent. Data presented here show that producers of crucifers used multiple pesticide applications in the 1990 season, an indication of the difficulty with which control was achieved. With a control cost of approximately $\$ 15$ per acre per application specifically for whitefly control, and with more than $95 \%$ of the fields needing at least one application, a conservative estimate of direct application costs for whitefly control was $\$ 217,184$ for the 15,240 acres grown in the fall of 1990 . We suspect the reduction in yields caused by the whitefly infestation was much greater than this value.

Secondly, the introduction of the poinsettia strain has altered the seasonal life cycle to approximate that which is found in other parts of the world. In India, $B$. tabaci overwinters on several weeds and cultivated cole crops. From these overwintering hosts adults emerge and multiply at the end of January, migrating to spring cucurbits by the end of March where rapid multiplication takes place. In the Imperial Valley, sugarbeets are near harvest at the end of March, but many of the 35,400 acres (1990 figures) have become infected with LIYV during the previous fall. Therefore one of the problems may be that large numbers of whiteflies in the spring will spread LIYV from this inoculum source into spring cucurbits. This LIYV-induced disease may add to problems associated with whitefly feeding (reduced yield and production of sooty mold which must be washed from melons prior to packing). We found evidence of a shift in seasonal occurrence of sweetpotato whiteflies in April of 1991. High numbers of B. tabaci infested several spring melon fields even though the valley had been exposed to abnormally cold winter conditions, which should have resulted in lower whitefly numbers.

From the spring melons, more whiteflies were present early in the cottongrowing season, thus cotton sustained greater damage sooner than that which was present in past years. And, since the poinsettia strain produces more honeydew than the cotton strain, there were more problems with "sticky cotton" (the contamination of cotton bolls by honeydew and sootymold fungus).

The abundance of $B$. tabaci continued to increase through August, when fall cucurbits and crucifers were planted. Since the poinsettia strain reached higher densities in cotton, larger numbers migrated to fall vegetables on which they colonized. With the feeding damage to fall crucifers and cucurbits and the LIYV problems in cucurbits, lettuce, sugar beets, and carrots, we believe that damage attributed to the introduction of $B$. tabaci, poinsettia strain, will exceed the $\$ 100$ million damage values attributed to the cotton strain, quoted by Duffus and Flock (see the NovemberDecember 1982 California Agriculture). Whiteflies likely will overwinter on the winter cruciferous crops to repeat the cycle.

Third and equally important, the poinsettia strain of $B$. tabaci in the southwest desert may lead to the occurrence of other vegetable disorders. In 1989, we sent sweetpotato whiteflies (cotton strain) from California to Florida to be tested side-by side with the poinsettia strain for the production of squash silverleaf. Our strain was shown not to cause silverleaf. However, this disease was observed in Arizona in 1989 and we found it in Southern California agricultural regions in April 1991. Here, we also report the first recorded incidence of tomato irregular ripening in California, which was identified on $B$. tabaci-infested plants growing in a garden in El Centro, California. These two disorders likely will exacerbate production problems for squash and tomato growers, therefore we urge vegetable producers in the southwest desert and other growing areas in California to be on the alert for these new sweetpotato whitefly-related disorders.

T. M. Perring, A. Cooper and D. J. Kazmer are Associate Professor, Laboratory Assistant, and Graduate Research Assistant, respectively, Department of Entomology, UC Riverside. C. Shields and J. Shields are pest control advisors in the Imperial Valley.

We wish to thank Vonifasio Vasquez, Keith Mayberry, Frank Laemmlen, Eric Natwick, Phyllis Cason, and Dick Weddle for their assistance in this research project. We also thank Neil Gerber for his cooperation while we investigated irregular ripening. Chuck Farrar, Matthew Blua, Frank Laemmlen, and Eric Natwick provided useful comments on earlier drafts of the manuscript. This research was funded, in part, by grants from the California Melon $\mathrm{Re}$ search Advisory Board and the California Iceberg Lettuce Research Program. 